\title{
FORMULASI DAN EVALUASI FLOATING SYSTEM TABLET DIFENHIDRAMIN HCI MENGGUNAKAN KOMBINASI MATRIKS HPMC K4M DAN Na. CMC
}

\author{
Formulation and Evaluation of Floating System Tablet Diphenhydramine $\mathrm{HCl}$ Using \\ A Combination of Matrix HPMC K4M and Na. CMC
}

\section{Khusnul Berty Indartantri'}

Noval ${ }^{1}$

Husda Oktaviannor ${ }^{3}$

*IPharmacy Department, Health Faculty, Sari Mulia University, Banjarmasin City, South Borneo 70238, Indonesia

2Health Promotion Department, Health Faculty, Sari Mulia University, Banjarmasin City, South Borneo 70238, Indonesia

*email:

khusnulberti@gmail.com

\begin{abstract}
Abstrak
Floating system tablet dibuat menggunakan matriks HPMC K4M dan Na. CMC dengan zat aktif difenhidramin $\mathrm{HCl}$ yang penyerapannya di lambung. Penelitian bertujuan untuk mengetahui pengaruh kombinasi matriks HPMC K4M dan $\mathrm{Na}$. CMC yang optimal pada formulasi floating system. Penelitian menggunakan metode eksperimental dengan rancangan RAL. Tablet dibuat dengan metode kempa langsung dan dilakukan evaluasi. Hasil kemudian di analisis statistik menggunakan One Way ANOVA. Hasil uji loss on drying, uji pengetapan, dan pengukuran sudut diam semua formulasi memenuhi persyaratan. Kecepatan alir serbuk semua formulasi tidak sesuai persyaratan. Tablet yang dihasilkan berwarna putih, pahit, bulat, dan berbau obat. Tablet pada semua formulasi memiliki keseragaman bobot sesuai persyaratan. Hasil uji kekerasan menunjukkan hanya formulasi 3 yang memenuhi persyaratan, sedangkan pada uji kerapuhan semua formulasi tidak memenuhi persyaratan. Pada uji lag time didapatkan hasil pada formulasil dan formulasi 2, formulasi 3, dan formulasi 4 adalah 4 detik, 4 detik, 3 detik, dan I detik, sedangkan hasil floating time menunjukkan semua formulasi dapat mengambang selama 24 jam. Semua hasil evaluasi menunjukkan bahwa formulasi yang optimal adalah formulasi 3.
\end{abstract}

Kata Kunci:

Pengetahuan

Minat

Pembalut

\section{Keywords:}

Knowledge

Interests

Bandages

\begin{abstract}
Floating system tablet was made using HPMC K4M and Na matrices. CMC with the active substance diphenhydramine $\mathrm{HCl}$ which absorption in the stomach. The research aims to determine the effect of a combination of HPMC K4M and Na. CMC matrices optimal in a floating system formulation. This research used an experimental method with a RAL design. Tablets were made by direct compression and were evaluated. The results were then analyzed statistically using One Way ANOVA. The results of the loss on drying test, the tapped density test, and measurement of the angle of repose of all formulations met the requirements. The powder flow rates of all formulations did not meet the requirements. The resulting tablet is white, bitter, round, and smells of medicine. Tablets in all formulations have uniform weight according to requirements. The hardness test results showed that only formulation 3 met the requirements, while in the friability test all formulations did not meet the requirements. In the lag time test, the results obtained in formulation $I$ and formulation 2, formulation 3, and formulation 4 are 4 seconds, 4 seconds, 3 seconds, and I second, while the floating time results show that all formulations can float for 24 hours. All evaluation results indicate that the optimal formulation is formulation 3.
\end{abstract}

C year The Authors. Published by Institute for Research and Community Services Universitas Muhammadiyah Palangkaraya. This is Open Access article under the CC-BY-SA License (http://creativecommons.org/licenses/by-sa/4.0/). DOI: https://doi.org// 0.33084/jsm.vxix.xxx.

\section{PENDAHULUAN}

Bentuk sediaan oral sebagian besar memiliki keterbatasan fisiologis seperti tingkat pengosongan lambung yang tidak terduga, waktu transit obat di gastrointestinal, dan adanya penyerapan di usus kecil bagian atas. Beberapa obat sangat sulit untuk tinggal di perut dalam jangka waktu yang lama (Vekariya et al., 20I5). Banyak sistem pendekatan yang telah dikembangkan untuk memberikan solusi untuk masalah tersebut salah satunya adalah sistem floating 
(mengambang). Sistem floating itu sendiri membuat atau mengharapkan agar sediaan tetap mengapung atau mengambang pada cairan lambung yang memberikan retensi dan pelepasan obat (Vekariya et al., 2015). Pembuatan floating tablet lebih disukai karena dapat meningkatkan kepatuhan pasien, ekonomis, dan menguntungkan untuk obat yang diserap di lambung seperti garam besi dan untuk obat-obatan yang ditujukan utuk efek lokal di lambung seperti antasida, dan obat dengan jendela serapan sempit (Begum et al., 20I4).

Difenhidramin $\mathrm{HCl}$ merupakan antihistamin yang termasuk dalam kelompok antagonis reseptor $\mathrm{HI}(\mathrm{HI}$ bloker) generasi pertama yang memiliki sifat sedatif dan anti alergi (Pubchem, 2019). Difenhidramin $\mathrm{HCl}$ diserap lambat pada saluran cerna dan memiliki waktu paruh 6,09 \pm I,0 jam (Alabazi \& Elzein, 20I2). Obat ini juga memiliki jendela penyerapan terapeutik sempit di gastrointestinal tract (Singh \& Pathak, 2016). Difenhidramin $\mathrm{HCl}$ dibuat floating system tablet agar mengurangi frekuensi pemakaian sehingga dapat meningkatkan kepatuhan pasien.

Pembuatan floating tablet ini menggunakan kombinasi dari matriks HPMC K4M dan Na. CMC. Matriks HPMC K4M dan Na. CMC termasuk ke dalam tipe matriks hidrofilik. Penggunaan matriks hidrofilik sebagai cara untuk mengendalikan pelepasan zat aktif (Siregar \& Wikarsa, 2010). Hasil penelitian menunjukkan bahwa matriks HPMC yang dikombinasikan dengan matriks $\mathrm{Na}$. CMC dapat membuat floating tablet yang memiliki pelepasan dan karakteristik mengambang yang sesuai (Fouladi $F$, Mortazavi SA., 20I2). Berdasarkan uraian di atas, peneliti ingin membuat floating system tablet difenhidramin $\mathrm{HCl}$ dengan menggunakan kombinasi dari matriks HPMC K4M dan Na. CMC serta melakukan evaluasi pada floating system tablet difenhidramin $\mathrm{HCl}$ untuk mengetahui formulasi yang optimal.

\section{METODOLOGI}

\section{Alat dan Bahan}

Alat yang digunakan pada penelitian antara lain neraca analitik (Shimadzu Corporation ATX224), alat-alat gelas (Pyrex), oven (Memmert Models 30-1060), pengayak (Sieve Shaker SS-200), alat pengetapan (Tap Density Tester TDT-2-H), alat uji sifat alir (Granule Flow Tester GFT-I00-AU), alat kempa tablet single punch, alat uji kekerasan (Hardness Tester), dan alat uji kerapuhan (Friability Tester TFT-2-D).

Bahan yang digunakan pada penelitian antara lain Difenhidramin $\mathrm{HCl}$, HPMC K4M (ILE Pharmaceutical Materials Cc, Ltn), Na. CMC (Ashland Material), Mg. stearat, Asam sitrat, $\mathrm{NaHCO}_{3}$, Talk, Avicel pH 102, Laktosa, Aquadest, dan $\mathrm{HCl} \mathrm{0,I} \mathrm{N.}$

\section{Metode Pelaksanaan}

I. Pembuatan floating system tablet difenhidramin $\mathrm{HCl}$ Pembuatan tablet menggunakan metode kempa langsung.

Tabel I. Formulasi floating system tablet difenhidramin $\mathrm{HCl}$

\begin{tabular}{lcccc}
\hline \multirow{2}{*}{ Bahan } & \multicolumn{4}{c}{ Formulasi (mg) } \\
\cline { 2 - 5 } & FI & F2 & F3 & F4 \\
\hline $\begin{array}{l}\text { Difenhidramin } \\
\mathrm{HCl}\end{array}$ & 75 & 75 & 75 & 75 \\
\hline $\mathrm{HPMC} \mathrm{K4M}$ & 20 & 40 & 60 & 80 \\
\hline $\mathrm{Na} . \mathrm{CMC}^{\mathrm{N}}$ & 80 & 60 & 40 & 20 \\
\hline NaHCO & 60 & 60 & 60 & 60 \\
\hline Talk & 18,5 & 18,5 & 18,5 & 18,5 \\
\hline Mg. Stearat & 4 & 4 & 4 & 4 \\
\hline Asam Sitrat & 70 & 70 & 70 & 70 \\
\hline Avicel pH I02 & 67,5 & 67,5 & 67,5 & 67,5 \\
\hline Laktosa & 105 & 105 & 105 & 105 \\
\hline Bobot tablet & $\mathbf{5 0 0}$ & $\mathbf{5 0 0}$ & $\mathbf{5 0 0}$ & $\mathbf{5 0 0}$ \\
\hline
\end{tabular}

Pembuatan serbuk dengan menimbang semua bahan, kemudian di ayak dengan ayakan mesh 80. Semua bahan dicampurkan selama 20 menit kecuali Mg. stearat. Setelah itu ayak kembali dengan melalui saringan mesh 80. Hasil ayakan di campurkan dengan Mg. stearat sampai homogen (Pradana AT, Parfati N, Shira SA., 20I5). Lakukan evaluasi terhadap campuran 
Khusnul Berty, Noval, Husda Oktaviannoor. 2021. Formulation and Evaluation of Floating System Tablet Diphenhydramine HCl Using A Combination of Matrix HPMC K4M and Na. CMC

serbuk, kemudian cetak tablet dengan alat kempa dan lakukan evaluasi tablet.

2. Evaluasi

a. Uji Loss On Drying (LOD)

Uji ini menggunakan alat oven. Campuran serbuk yang sudah homogen di oven selama 2 jam pada suhu $105^{\circ} \mathrm{C}$ untuk melihat kadar air pada serbuk (Murtini \& Elisa, 2018).

\section{$\% \mathrm{LOD}=$}

$\frac{\text { Bobot granul awal-Bobot granul setelah pengeringan }}{\text { Bobot granul setelah pengeringan }} \times 100$

b. Uji Sifat Alir

Terdapat dua uji sifat alir antara lain pengukuran kece patan alir serbuk dan pengukuran sudut diam. Pada pengukuran kecepatan alir serbuk dilakukan dengan mengukur $100 \mathrm{~g}$ campuran serbuk menggunakan alat granule flow tester.

$$
\operatorname{Tg} \alpha=\operatorname{Tan}^{-1} 2 H / D
$$

\section{Keterangan:}

$\mathrm{H}$ : Tinggi serbuk yang terbentuk di atas bidang datar

D : Diameter serbuk yang terbentuk di atas bidang datar

c. Uji Pengetapan

Uji ini menggunakan alat Tapped density tester, campuran serbuk dimasukkan ke dalam alat sebanyak $100 \mathrm{ml}$, catat volume awal serbuk kemudian lakukan pengempaan dengan kecepatan dan waktu yang telah ditentukan lalu catat volume akhir serbuk (Hadisoewignyo \& Achmad, 2016).

$$
\% \text { Kompressibilitas }=\frac{V 0-V 1}{V 1} \times 100
$$

Keterangan:

$\mathrm{V}_{0}$ : Volume awal granul

$\mathrm{V}_{1}$ : Volume granul setelah diketukkan

d. Uji Organoleptis

Uji ini dilakukan untuk mengetahui bentuk, bau, warna, dan rasa dari floating system tablet difenhidramin $\mathrm{HCl}$ yang dibuat.

e. Uji Keseragaman Bobot
Tablet diambil secara acak sebanyak 20 tablet pada masing-masing formulasi. Kemudian tablet ditimbang menggunakan timbangan analitik, tentukan variasi bobot tablet dengan membandingkan bobot masing-masing tablet dengan bobot rata-rata tablet (Noval dkk, 2021).

f. Uji Kekerasan

Ambil 6 tablet, letakkan diantara dua landasan alat penguji kekerasan (Hardness Tester). Berikan beban pada tablet dari beban yang paling kecil, catat pada beban berapa tablet mengalami kerusakan (Irfan et al., 2016).

g. Uji Kerapuhan

Ambil 10 tablet kemudian ditimbang (WI), letakkan tablet dalam alat friability tester, lalu alat diopersikan dengan kecepatan 25 rpm selama 4 menit. Setelah itu tablet dikeluarkan dan dibersihkan dari serbuk yang menempel, lalu tablet ditimbang (W2). Lakukan replikasi sebanyak 3 kali, hitung persentase kerapuhannya (\%) (Putri \& Forestryana, 2017) (Noorjannah dan Noval, 2020).

$$
\% \text { Kerapuhan }=\frac{W 1-W 2}{W 1} \times 100 \%
$$

h. Uji Lag Time dan Floating Time

Pada uji lag time dan floating time, tablet dimasukkan ke dalam beker glass yang berisi $\mathrm{HCl} 0, \mathrm{I} N 250 \mathrm{ml}$ dengan $\mathrm{pH}$ I,2. Hitung waktu jeda mengambang (lag time) yang dilihat saat tablet mulai mucul ke permukaan dan mengapung, serta hitung waktu mengambang tablet (floating time) yang dilihat dari durasi tablet mengapung (Fitriani et al., 20l7).

\section{HASIL DAN PEMBAHASAN}

Evaluasi serbuk meliputi uji LOD, pengukuran kecepatan alir, pengukuran sudut diam, dan uji pengetapan yang dapat dilihat pada tabel II. 
Tabel II. Hasil evaluasi serbuk

\begin{tabular}{ccccc}
\hline \multicolumn{5}{c}{ Hasil Evaluasi Serbuk } \\
\hline Formulasi & $\begin{array}{c}\text { LOD } \\
(\%)\end{array}$ & $\begin{array}{c}\text { Kecepatan } \\
\text { Alir (detik) }\end{array}$ & $\begin{array}{c}\text { Sudut } \\
\text { Diam } \\
\left({ }^{(}\right)\end{array}$ & $\begin{array}{c}\text { Pengetapan } \\
(\%)\end{array}$ \\
\hline 1 & 2,81 & 15 & 29,78 & 13,49 \\
\hline 2 & 3,14 & 13 & 30,86 & 14,42 \\
\hline 3 & 2,94 & 13 & 28,40 & 13,7 \\
\hline 4 & 3,89 & 14 & 29,06 & 14,07 \\
\hline
\end{tabular}

Persyaratan kadar air yaitu kurang dari 2-4\% atau pada rentang 2-5\% (Murtini \& Elisa, 2018; Pujiastuti et al., 2019). Hasil evaluasi uji LOD pada tabel II menunjukkan campuran serbuk pada semua formulasi memenuhi syarat kadar air yang baik. Hasil penelitian ini sejalan dengan hasil penelitian lain yang menunjukkan hasil rata-rata uji LOD ketiga formulasi pada pembuatan tablet ekstrak daun kemuning adalah I,06\% yang masih memenuhi persyaratan (Fitriana et al., 2010).

Syarat uji waktu alir adalah 10 detik untuk $100 \mathrm{~g}$ campuran serbuk atau granul, jika lebih dari 10 detik maka campuran serbuk atau granul dikatakan mengalir bebas (Murtini \& Elisa, 2018). Hasil pada tabel II menunjukkan pada semua formulasi tidak memenuhi syarat kecepatan alir yang baik. Faktor yang mempengaruhi sifat alir yaitu campuran serbuk pada semua formulasi memiliki ukuran partikel yang kecil, yang dapat mempengaruhi sifat adhesi dan kohesi menjadi lebih besar (Taufikurrahmi et al., 2017). Selain itu, perbedaan ukuran diameter antara lubang corong alat granul flow tester dengan lubang corong alat kempa tablet dapat mempengaruhi hasil uji kecepatan alir serbuk (Dja'far \& Satria, 2017).

Syarat sudut diam pada campuran serbuk atau granul yang baik yaitu kurang dari $42^{\circ}$ (Rori et al., 2016). Hasil pada tabel II menunjukkan setiap formulasi sudah memenuhi persyaratan. Hasil penelitian yang mengukur sudut diam pada pembuatan tablet vitamin $E$ menunjukkan hasil yang juga memenuhi persyaratan sudut diam yaitu $30,4^{\circ}$ (Mariyani \& Setyawan, 2012).
Hasil kompresibiltas dengan rentang 12-16\% dikatakan memiliki kriteria aliran yang baik (Murtini \& Elisa, 2018). Hasil evaluasi pada tabel 2 menunjukkan semua formulasi memenuhi syarat kompresibilitas. Faktor yang dapat mempengaruhi kompresibilitas yaitu ukuran partikel dan kerapatan (Kholidah \& Khumaidi, 20I4). Ukuran partikel yang kecil memiliki kerapatan yang lebih besar daripada ukuran partikel yang lebih besar (Gozali et al., 2016). Penelitian ini sejalan dengan penelitian sebelumnya pada pembuatan tablet ekstrak kangkung air dalam pengujian pengetapan serbuk yang mana didapatkan hasil rata-rata ketiga formulasinya sebesar 14,77\% (Khaidir et al., 2015).

Evaluasi fisik floating system tablet difenhidramin $\mathrm{HCl}$ meliputi uji organoleptis, keseragaman bobot, kekerasan dan kerapuhan. Hasil evaluasi uji organoleptis dapat dilihat pada gambar I yang menunjukkan tablet berwarna putih, pahit, berbentuk bulat, dan berbau obat.

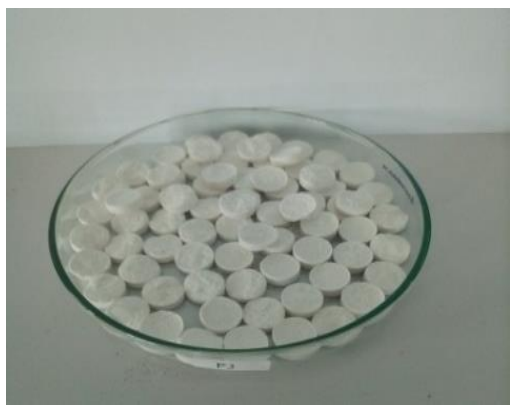

Gambar I. Hasil uji organoleptis

Hasil evaluasi uji keseragaman bobot dapat dilihat pada tabel III. Hasil perhitungan keseragaman bobot yang didapatkan yaitu semua formulasi memiliki bobot ratarata lebih dari $300 \mathrm{mg}$. Standar penyimpangan bobot rata-rata tablet yang memiliki bobot rata-rata lebih dari $300 \mathrm{mg}$ yaitu kolom A adalah 5\% dan kolom B adalah 10\% (Ditjen, 1979). Hasil perhitungan keseragaman bobot menunjukkan bahwa tablet pada semua formulasi tidak ada yang menyimpang dari persyaratan yang sudah ditentukan. Hasil penelitian sebelumnya pada pembuatan floating tablet dexhlorpheniramine maleat menunjukkan tablet yang dibuat memiliki bobot yang juga seragam atau memenuhi persyaratan yang 
Khusnul Berty, Noval, Husda Oktaviannoor. 2021. Formulation and Evaluation of Floating System Tablet Diphenhydramine HCl Using A Combination of Matrix HPMC K4M and Na. CMC

sudah ditentukan (Alabrazi \& Elzein, 2015). Hasil analisis statistik menunjukkan adanya perbedaan antar formulasi 2 dengan 3 dan formulasi 3 dengan 4 ( $p<$ 0,05).

Tabel III. Hasil uji keseragaman bobot

\begin{tabular}{ccccccc}
\hline \multirow{2}{*}{ No } & \multicolumn{3}{c}{ Bobot Tablet (mg) } & \multicolumn{2}{c}{$\begin{array}{c}\text { Penyimpangan } \\
\text { Bobot }\end{array}$} \\
\cline { 2 - 7 } & FI & F2 & F3 & F4 & $5 \%$ & I0\% \\
\hline I & 510 & 490 & 480 & 500 & + & + \\
\hline 3 & 510 & 490 & 490 & 500 & + & + \\
\hline 4 & 520 & 500 & 480 & 500 & + & + \\
\hline 5 & 500 & 480 & 480 & 510 & + & + \\
\hline 6 & 500 & 510 & 500 & 500 & + & + \\
\hline 7 & 500 & 480 & 480 & 510 & + & + \\
\hline 8 & 520 & 510 & 500 & 470 & + & + \\
\hline 9 & 510 & 500 & 490 & 470 & + & + \\
\hline 10 & 490 & 500 & 500 & 470 & + & + \\
\hline 11 & 470 & 470 & 520 & 500 & + & + \\
\hline 12 & 480 & 480 & 520 & 500 & + & + \\
\hline 13 & 470 & 470 & 510 & 500 & + & + \\
\hline 14 & 490 & 480 & 490 & 510 & + & + \\
\hline 15 & 470 & 480 & 500 & 500 & + & + \\
\hline 16 & 490 & 490 & 510 & 500 & + & + \\
\hline 17 & 490 & 480 & 490 & 510 & + & + \\
\hline 18 & 480 & 460 & 490 & 470 & + & + \\
\hline 19 & 480 & 480 & 510 & 470 & + & + \\
\hline 20 & 470 & 460 & 490 & 470 & + & + \\
\hline
\end{tabular}

Keterangan:

$(+)$ : bobot tablet seragam

Hasil uji kekerasan dan uji kerapuhan sebagai berikut.

Tabel IV. Hasil uji kekerasan dan uji kerapuhan

\begin{tabular}{ccc}
\hline \multicolumn{3}{c}{ Hasil Uji Kekerasan dan Kerapuhan } \\
\hline Formulasi & Kekerasan (Kg) & Kerapuhan (\%) \\
\hline 1 & 3,8 & 9,02 \\
\hline 2 & 3,3 & 8,42 \\
\hline 3 & 4 & 2,98 \\
\hline 4 & 3 & 10,58
\end{tabular}

Syarat uji kekerasan tablet yang baik yaitu minimal 4 $\mathrm{kg} / \mathrm{cm}^{3}$ atau 4-8 kg (Murtini \& Elisa, 20l8; Riyanti \& Rohmani, 2018). Hasil pada tabel IV menunjukkan bahwa formulasi yang memenuhi syarat kekerasan tablet hanya formulasi 3. Faktor yang mempengaruhi kekerasan antara lain gaya tekan pada saat proses pengempaan dan jenis bahan pengikat yag digunakan (Nariswara et al., 20I3). Pada formulasi bahan pengikat yang digunakan adalah avicel $\mathrm{pH}$ 102. Menurut penelitian penggunaan avicel $\mathrm{pH} \quad \mathrm{O} 2$ akan meningkatkan kekerasan tablet karena sifat kompaktibiltas avicel pH $\mathrm{IO}$ yang baik (Setyawan et al., 2010). Kemungkinan tablet tidak memenuhi persyaratan karena kurangnya gaya kompresi saat pencetakan tablet, jika tekanan kompresi ditambah maka nilai kekerasan tablet akan meningkat (Murtini \& Elisa, 2018). Nilai kekerasan pada hasil penelitian pembuatan tablet juga tidak sesuai yaitu $3,7 \mathrm{~kg} / \mathrm{cm}^{2}$, hal ini terjadi akibat kurangnya tekanan pada saat proses pengempaan tablet (Fitri et al., 2018). Hasil analisis statistik menunjukkan tidak ada perbedaan antar formulasi $(p>0,05)$.

Pada uji kerapuhan, syarat yang ditetapkan yaitu kehilangan bobot tablet setelah pengujian lebih kecil dari 0,5\% sampai I\% (Murtini \& Elisa, 20I8). Hasil pada tabel IV menunjukkan bahwa semua tablet tidak memenuhi syarat uji kerapuhan. Faktor yang mempengaruhi yaitu adanya jumlah fines yang banyak (Noval dkk, 202l). Jumlah fines yang terlalu banyak dapat menyebabkan tablet rapuh karena tersusun dari serbuk yang sangat halus sehingga kekerasannya rendah yang mengakibatkan kerapuhannya meningkat (Mariyani \& Setyawan, 20I2). Pengaruh tekanan pengempaan pada saat pencetakan juga dapat mempengaruhi, semakin tinggi tekanannya maka tablet akan semakin keras sehingga kerapuhan tablet akan rendah (Dewi \& Karim, 2019). Hasil analisis statistik menunjukkan terdapat perbedaan antar formulasi $(\mathrm{p}<$ $0,05)$.

Evaluasi uji lag time dan floating time pada floating system tablet difenhidramin $\mathrm{HCl}$ dapat dilihat pada tabel berikut.

Tabel V. Hasil Uji Lag Time dan Floating Time Floating System Tablet Difenhidramin $\mathrm{HCl}$

\begin{tabular}{ccc}
\hline \multicolumn{3}{c}{ Hasil Uji Lag Time dan Floating Time } \\
\hline Formulasi & Lag time (detik) & Floating time (jam) \\
\hline I & 4 & 24 \\
\hline 2 & 4 & 24 \\
\hline 3 & 3 & 24 \\
\hline 4 & I & 24 \\
\hline
\end{tabular}

Tablet yang baik ditandai dengan lag time kurang dari I menit dan floating time lebih dari 12 jam (Pradana et al., 2015). Hasil uji lag time dan uji floating time 
menunjukkan bahwa hasil yang diperoleh dari semua formulasi sudah memenuhi syarat yang ditentukan. Perbedaan lag time dapat dipengaruhi oleh berat molekul masing-masing polimer, semakin kecil nilai berat molekul polimer, semakin cepat tablet mengapung ke permukaan medium. Floating time juga dipengaruhi oleh kelarutan polimer yang digunakan sebagai matriks. Semakin lama matriks dilarutkan dalam medium, maka semakin lama pula matriks mengapung dipermukaan medium (Fitriani et al., 2017). Penelitian ini sejalan dengan penelitian sebelumnya pada pembuatan floating tablet ranitidine $\mathrm{HCl}$ dimana uji lag time dan uji floating timenya memenuhi persyaratan pada (Pradana et al., 20I5). Penelitian lain yang membuat floating tablet bupropion $\mathrm{HCl}$ dengan kombinasi matriks HPMC dan $\mathrm{Na}$. CMC juga menunjukan hasil yang baik dalam pengujian lag time dan floating timenya (Fouladi \& Mortazavi, 20I2).

\section{KESIMPULAN}

Pengaruh kombinasi matriks HPMC K4M dan $\mathrm{Na}$. CMC pada floating system tablet difenhidramin $\mathrm{HCl}$ yaitu dapat dilihat pada hasil sifat fisik tablet, lag time, dan floating time. Hasil evaluasi sifat fisik tablet menunjukkan bahwa formulasi 3 lebih baik dibandingkan formulasi lainnya dikarenakan pada formulasi 3 konsentrasi HPMC K4M dan Na. CMC sudah optimal yaitu konsentrasi HPMC K4M $60 \mathrm{mg}$ dan konsentrasi $\mathrm{Na}$. CMC $40 \mathrm{mg}$.

\section{UCAPAN TERIMA KASIH}

Penulis mengucapkan terima kasih kepada seluruh pihak yang sudah membantu dalam proses pengerjaan maupun penyusunan penelitian ini dan juga kepada Laboratorium Teknologi Farmasi Universitas Sari Mulia Banjarmasin yang telah menyediakan tempat serta keperluan untuk penelitian.

\section{REFERENSI}

I. Vekariya, D., Pujara, N., Kanzariya, V., \& Doshi, S.
(2015). Formulation and Evaluation of Cinnarizine Floating Tablet for Improved Formulation and Evaluation of Cinnarizine Floating Tablet for Improved Absorption. 2013(September 2013), I-5

2. Begum, M. Y., Avanthi, J., Shwetha, A., Madhuri, T., Sudhakar, M., \& Naveen, D. (20/4). Formulation And Evaluation Of Sustained Release Floating Tablets Of Loratadine. International Journal of Pharmaceutical Sciences And Research, 5(10), 4375-4385.

https://doi.org/10.1017/CBO978I I074I5324.004

3. Pubchem. (2019). Diphenhydramine.

4. Alabazi, M. Y., \& Elzein, H. (20I2). An approach to formulating an oral floating drug delivery system for dexchlorpheniramine maleate using factorial design. Pharmazie, 67(7), 611-617. https://doi.org/10.1691/ph.2012.1137

5. Singh, S., \& Pathak, K. (2016). Assessing the biodhesivity of Acconon MC 8-2 EP/NF for gastroretention of floating microsponges of loratadine and achieving controlled drug delivery. Pharmaceutical and Biomedical Research, 2(2), 5874. https://doi.org//0.18869/acadpub.pbr.2.2.9

6. Fouladi, F., \& Mortazavi, S. A. (2012). Preparation and in-vitro evaluation of gastroretentive bupropion hydrochloride tablets. Tropical Journal of Pharmaceutical Research, II(3), 35I-359. https://doi.org//0.43|4/tipr.vI Ii3.3

7. Pradana, A. T., Parfati, N., \& Shira, S. A. (20/5). Formulasi Floating Tablet Menggunakan Variasi Konsentrasi HPMC KI00M Terhadap Kemampuan Mengapung Dan Profil Disolusi Tablet Ranitidine $\mathrm{HCl}$. Jurnal Ilmiah Sains \& Teknologi, 9(I), II-2I.

8. Hadisoewignyo, L., \& Achmad, F. (2016). Sediaan Solida Edisi Revisi. Pustaka Pelajar.Care and Sciences, I (I), 45-54.

9. Noval, N., Appriliani, R., \& Oktaviannoor, H. (202I). Evaluasi Pengaruh Konsentrasi Pati Biji Cempedak (Artocarpus champeden) sebagai Bahan Pengisi pada Formulasi Tablet Paracetamol. Jurnal Surya Medika (JSM), 6(2), IIII 18. https://doi.org/10.33084/jsm.v6i2.2127.

10. Irfan, M., Akram, A., Zahoor, A. F., Qadir, M. I., 
Khusnul Berty, Noval, Husda Oktaviannoor. 2021. Formulation and Evaluation of Floating System Tablet Diphenhydramine HCl Using A Combination of Matrix HPMC K4M and Na. CMC

Hussain, A., Abbas, N., Khan, A., Arshad, M. S., \& Khan, N. I. (20|6). Formulation parameters affecting floating behaviour and drug release from extended release floating tablets of ranitidine hydrochloride. Latin American Journal of Pharmacy, $35,1206-1216$.

II. Putri, A. N., \& Forestryana, D. (2017). Formulasi dan Karakterisasi Fisik Tablet Floating Mukoadhesif Ranitidin $\mathrm{HCl}$. Jurnal Pharmascience, $4(2)$, 176-186. https://doi.org//0.20527/jps.v4i2.577|

12. Noorjannah, N., \& Noval, N. (2020). Uji Disolusi Terbanding Antara Sediaan Tablet Ramipril Generik Dan Bermerek. Journal of Pharmaceutical

13. Fitriani, L., Abdillah, R., \& Ben, E. S. (2017). Formulation of Metformin $\mathrm{HCl}$ Floating Tablet using HPC , HPMC KIOOM, and the Combinations. 4(2), 79-82. https://doi.org//0.29208/jsfk.2017.4.1.201

14. Murtini, G., \& Elisa, Y. (20I8). Bahan Ajar Farmasi Teknologi Sediaan Solid. In Kementrian Kesehatan Republik Indonesia (Pertama). Kementrian Kesehatan Republik Indonesia. https://doi.org/10.1017/CBO978II07415324.004

I5. Fitriana, Y., Sunarni, T., \& Priyanto, W. (20/0). Pengaruh Bahan Pengikat Gelatin dalam Formula Tablet Ekstrak Daun Kemuning (Murraya paniculata (L.) Jack) secara Granulasi Basah. Jurnal Farmasi Indonesia, 7(2), 67-72.

16. Taufikurrahmi, Kharimah, H., Fatmawati, H. D., Hidayatullah, S., \& Chabib, L. (2017). Pengaruh Variasi Bahan Penghancur terhadap Sifat Fisikokimia dan Disolusi Tablet Aminofilin sebagai Terapi Asma. Jurnal Pharmascience, 04(0I), 74-84.

17. Dja'far, S., \& Satria, F. (2017). Perbandingan Mutu Fisik Tablet Parasetamol Menggunakan Metode Gelatinasi Dan Pragelatinasi Dengan Penambahan Bahan Pengikat Pati Singkong (Amylum manihot ). Akademi Farmasi Putra Indonesia, 3(I), I-I0.

18. Rori, W. M., Yamlean, P. V., \& Sudewi, S. (20I6). Formulasi Dan Evaluasi Sediaan Tablet Ekstrak Daun Gedi Hijau (Abelmoschus manihot) Dengan Metode Granulasi Basah. Formulasi Dan Evaluasi Sediaan Tablet Ekstrak Daun Gedi Hijau (Abelmoschus Manihot) Dengan Metode Granulasi
Basah,

$5(2)$,

$243-250$

https://doi.org//0.2307/j.ctvswx8f2.8

19. Mariyani, K. A., \& Setyawan, E. I. (20I2). Pengaruh Konsentrasi Amilum Jagung Pregelatinasi sebagai Bahan Penghancur ( Ayu , M ., Pengaruh Konsentrasi Amilum Jagung Pregelatinasi sebagai Bahan Penghancur ( Ayu , M ., Sri , A ., Eka , I . S .). I(I), 39-49.

20. Kholidah, S., \& Khumaidi, A. (20/4). Formulasi Tablet Effervescent Jahe (Z Officinale Roscoe) Dengan Variasi Konsentrasi Sumber Asam Dan Basa. Online Jurnal of Natural Science, 3(3), 216229.

2I. Gozali, D., Susilawati, Y., Simorangkir, T. P. H., \& Utami, N. F. (2016). Formulasi Tablet Hisap Yang Mengandung Ekstrak Aakar Ginseng Korea ( Panax ginseng C.A. Meyer) dan Ekstrak Rimpang Temulawak ( Curcuma xanthorrhiza ROXB .) (Vol. 8, Issue I).

22. Ditjen, P. (1979). Farmakope Indonesia Edisi III (III). Departemen Kesehatan Republik Indonesia.

23. Alabrazi, M., \& Elzein, H. (20/5). The study of differences between MCC and DCP as a diluent in the evaluation of dexchlorpheniramine maleate floating tablet. International Journal of Pharmaceutical Sciences Review and Research, 3I(I), |07-II2.

24. Nariswara, Y., Hidayat, N., \& Effendi, M. (20/3). Pengaruh Waktu Dan Gaya Tekan Terhadap Kekerasan Dan Waktu Larut Tablet Effervescent Dari Serbuk Wortel (Daucus Carota L.). Jurnal Industria, 2(I), 27-35.

25. Fitri, Y. A., Ferdiansyah, R., \& Legowo, W. P. (2018). Pengaruh variasi konsentrasi kalium sulfat terhadap karakteristik karagenan dan aplikasinya sebagai pengisi sediaan tablet. Jurnal Farmasi Galenika, 5(2), 56-70.

26. Noval, N., \& Rosyifa, R. (202I). Dispersi Padat untuk Peningkatan Laju Disolusi Natrium Diklofenak dengan Variasi Konsentrasi Polivinil Pirolidon K30. Jurnal Surya Medika (JSM), 6(2), 94I0I. https://doi.org/10.33084/jsm.v6i2.2125.

27. Dewi, S. T. R., \& Karim, D. (2019). Pengaruh 
Penggunaan Serbuk Umbi Talas (Colocasia esculenta L.Scoot) sebagai Bahan Pengikat Dalam Pembuatan Tablet Parasetamol. Media Farmasi, $X V I(I), I-6$. 